\title{
Kinetic of 4-Chlorophenols Biodegradation by Arthrobacter Chlorophenolicus A6
}

\author{
Naresh Kumar Sahoo
}

\begin{abstract}
Chlorophenols are listed as priority pollutants both by European community and US EPA. Biodegradation of pchlorophenol (4-CP) was investigated in batch shake flasks by Arthrobacter chlorophenolicus A6 at initial 4-CP concentrations between 25 to $350 \mathrm{mgl}-1$. The rate of $4-C P$ removal decreased with increasing initial 4-CP concentrations due to toxic effects on the microorganisms. The growth and biodegradation kinetic of the culture was evaluated. The batch growth profile of the $A$ chlorophenolicus A6 followed substrate inhibition kinetics with the estimated biokinetic parameters of Ksi $=272 \mathrm{mgl}-1, \mathrm{Ks}=65$ mgl-1 for 4-CP respectively. High inhibition constant (KSI $=272$ $m g-l)$ with a $\mathrm{KSI} / \mathrm{KS}$ ratio of 4.18 indicates superior 4-CP biodegradation potential of the $A$ chlorophenolicus A6. The maximum rate of 4-CP degradation has been achieved at an optimum substrate concentration of Smax $=($ KSKSI $) 1 / 2=$ $(65 \times 272) 1 / 2=133 \mathrm{mgl}-1$.
\end{abstract}

keywords: Biodegradation, Arthrobacter chlorophenolicus A6, 4-Chlorophenol, Substrate inhibition kinetics.

\section{INTRODUCTION}

The major industries associated with chlorophenol are such as petrochemical, pharmaceutical, wood preserving, integrated iron and steel plant, pesticide and paper $[1,2,3]$. Further during the disinfection of drinking water and bleaching of pulp in paper industry significant amount of chlorinated phenol are produces. Therefore, effluent from these above mentioned industries causes a severe human health hazards as well serious damage to the environment. Chlorophenol is one of the hazardous waste and placed in166th position out of the 1467 number of the national priority pollutant list as per US EPA. Chronic exposure of chlorophenol from polluted environment is suspected to be carcinogen and is highly embryo toxic in nature [4,5]. Similarly also exhort toxicity to aquatic organisms [6]. Wild et al, [7] reported the concentration of primary pollutants present in 12 sewage sludge's such as; $19.6--86.3 \mathrm{~g} / \mathrm{L}$ of 2,4dichlorophenol. However maximum allowed chlorophenol concentration is $10 \mu \mathrm{g} / \mathrm{L}$ in drinking water [8]. The above mentioned chlorophenol concentration in the industrial effluent and sewage sludge are beyond the permissible limit, so there is a urgent need to enhance the rate and concentration of chlorophenols removal from wastewater. There are several methods available in treatment of phenolic wastewater for instance; volatilization, adsorption, photocatalytic degradation, electrochemical methods, and solvent extraction [9]. However, poor efficiency, generation of toxic by product and high cost, are the major drawback of these removal strategies. The eco friendly biodegradation method is an attractive alternative to the above mentioned traditional methods. There are several reports available in literature on biodegradation of chlorophenols by mixed culture and pure culture bacterial species such as Flavobacterium sp., Pseudomonas sp., Sphingomonas sp., Mycobacterium sp., Flavobacterium sp., Rhodococcus sp., Streptomyces sp., Arthrobacter sp., etc are the most potential species. Among the various species, actinomycetes can secret both, extracellular as well as intracellular enzymes thus this species is able to degrade chlorophenols efficiently. Furthermore, the active cleft of the enzymes are altered mainly at leu80, Asp83, Val107aminoacids positions, which facilitates its broad specificity nature in degradation of wide different type of pollutants present in real industrial wastewater and can interact with wide different toxic substrates occur in actual industrial wastewater, along with chlorophenols [10]. It is highly essential to enhance the rate and concentration of chlorophenol biodegradation.

In order to design and optimize the operational conditions for treatment of contaminated wastewater using bioreactor system, knowledge on pollutant biodegradation kinetics and microbial growth profile is playing the vital role. However, biomass growth and 4-chlorophenol degradation kinetic using actinomycetes strain is very scanty. Although actinomycetes are the proved to be the most efficient species in chlorophenol biodegradation however, only limited reports are available on biodegradation of the chlorophenol by actinomycetes species. The present investigation demonstrates the growth and 4-CP degradation kinetics of $\mathrm{A}$ chlorophenolicus A6, at diffrent initial concentration of chlorophenol have been evaluated.

\section{MATERIALS METHODS}

\section{A. Chemicals and Reagents}

Analytical grade 4-CP was procured from Sigma Aldrich (Germany). All other chemicals and reagents used in the study were procured from Merck (India), HiMedia, (Mumbai, India).

\section{B. Preparation of Inoculums}

The biodegradation of 4-CP was carried out by employing a minimum salts medium (MSM) (g 1-1: K2HPO4 2.6, NH4NO3 0.58, KH2PO4 0.4, MgSO4 0.17, FeCl3 0.002 and $\mathrm{CaCl} 2$ 0.038) and $\mathrm{pH} 7.4$, with $300 \mathrm{mgl}-1$ 4-CP [11]. The seed culture cells were grown in the above mentioned MSM with $0.3 \%$ yeast extract in an incubator shaker for 40 $\mathrm{h}$ at $30^{\circ} \mathrm{C}$ and $210 \mathrm{rpm}$. Then the cells centrifuged $(8000 \mathrm{~g}$ 
at $10^{\circ} \mathrm{C}$ ) and were washed in sterile phosphate buffer (PBS, $\mathrm{pH}$ 7.5). Then the microbial cells were adapted to 4-CP by growing overnight with MSM containing $300 \mathrm{mgl}-1$ of 4-CP as the only carbon source. After this adaptation period the cells were centrifuged $\left(8000 \mathrm{~g}, 15 \mathrm{~min}\right.$ at $\left.10^{\circ} \mathrm{C}\right)$, washed in $1 \mathrm{X}$ PBS (pH 7.5) and were then employed as the inoculums for the degradation of 4-CP . The initial biomass concentration in the inoculums was 0.1 OD600nm.

\section{Growth and degradation kinetic of 4-CP}

Shake flask experiments were carried out by using Erlenmeyer flasks $(250 \mathrm{~mL})$ were charged with $100 \mathrm{~mL}$ of optimised mineral salt media as mentioned earlier. Different amounts of 4-CP were added to the separately to each flasks to yield 4-CP concentrations at a level of 25, 50, 100, 200, $250,300,350 \mathrm{mgl}-1$ respectively. Rest of the experimental procedure were similar to as above.

\section{Analytical Methods}

Estimation of biomass concentration was performed by measuring its optical density (OD600nm) in a UV-visible spectrophotometer (Perkin Elmer U.S.A, Model lambda-45). 4-CP concentration of 4-CP from the collected samples were measured by reverse phase HPLC system employing an Onsphere C-18 column (Varian Prostar 210). Detection of 4$\mathrm{CP}$ was carried out using a UV detector at wavelength of $280 \mathrm{~nm}$. The mobile phase used in the estimation of 4-CP was a mixture of acetonitrile-water (80:20, v/v). The experiment was carried out at a flow rate of $0.8 \mathrm{ml} / \mathrm{min}$ and at $28^{\circ} \mathrm{C}$ and the retention time of $4-\mathrm{CP}$ was observed at 5.6 $\min$.

\section{RESULTS AND DISCUSSION}

\section{A. Growth and degradation kinetic of 4-CP}

Figure 1 demonstrates variation of 4-CPdegradation rates with initial concentration of 4-CP. It is observed from the Figure1 that, the rate of 4-CP degradation increases with increase in initial 4-CP concentration up to $100 \mathrm{mgl}^{-1}$, On the other hand, rate of 4-CP decreases when the initial 4-CP concentration increases beyond $100 \mathrm{mgl}^{-1}$. This observation clearly reveals substrate inhibitory effects of 4-CP on the microbial cell at concentrations more than $100 \mathrm{mgl}^{-1}$. In this conditions the degradation rate of 4-CP declines from 20 to $8 \mathrm{mgl}^{-1} \mathrm{~h}^{-1}$ when initial concentration of 4-CP raises from 140 to $350 \mathrm{mgl}^{-1}$. Since the actinomycetes strain follows a typical substrate inhibition kinetics patterns as shown in Figure 1, a literature existing non-competitive substrate inhibition kinetics model was applied to estimate the biokinetic parameters associated with degradation of 4-CP by the A chlorophenolicus A6 as follows [12].

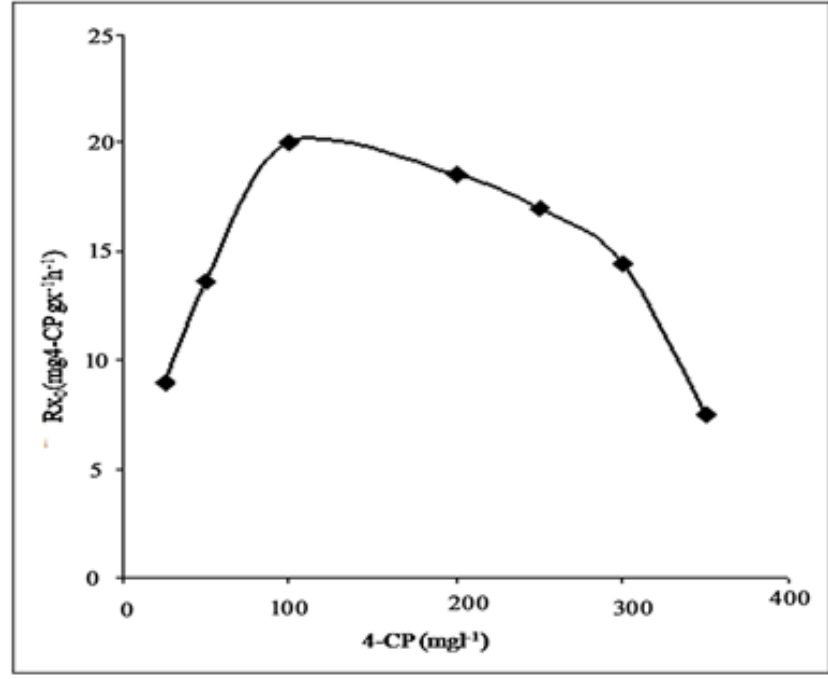

Figure1. Variation of 4-CP specific degradation rate with change in initial concentration.

$$
\begin{aligned}
& R_{S 0}=\frac{k X_{0} S_{0}}{K_{S}+S_{0}} \frac{K_{S I}}{K_{S I}+S_{0}}=\frac{k X_{0}}{\left(1+K_{S} / S_{0}\right)\left(1+S_{0} / K_{S I}\right)} \\
& R_{X 0}=\frac{R_{S 0}}{X_{0}}=\frac{k S_{0}}{K_{S}+S_{0}} \frac{K_{S I}}{K_{S I}+S_{0}}
\end{aligned}
$$

Where, $S_{\mathrm{o}}$ stands for the initial concentration of 4-CP $\left(\mathrm{mgl}^{-1}\right), X_{\mathrm{o}}$ represents the initial biomass concentration of the actinomycetes culture $\left(\mathrm{mgl}^{-1}\right), R_{\text {so }}$ is denotes for 4-CP degradation rate $\left(\mathrm{mg} 4-\mathrm{CP} 1^{-1} \mathrm{~h}^{-1}\right), K_{\mathrm{S}}$ represents the half saturation constant $\left(\mathrm{mgl}^{-1}\right), k$ stands for the rate of biodegradation constant $\left(\mathrm{h}^{-1}\right)$ and $K_{\mathrm{SI}}$ represents the inhibition constant on microbial cell due to 4-CP $\left(\mathrm{mgl}^{-1}\right)$. $R_{\text {so }}$ is determined by using the initial concentration versus time and the slope gives the rate $\left(\mathrm{mgl}^{-1} \mathrm{~h}^{-1}\right)$. The specific rate of 4-CP degradation $\left(R_{\mathrm{xo}}\right)$ can be calculated as $R_{\mathrm{so}} / X_{\mathrm{o}}$ where $X \mathrm{o}$ is $0.014 \mathrm{gl}^{-1}$. The first term in equation (1) correspond to Monod rate expression for the rate of 4-CP biodegradation by the actinomycetes species. Whereas, the second term of the equation (1) indicates the non-competitive substrate inhibition pattern of 4-CP on the microbial cells. When the initial concentrations of 4-CP is low (4-CP $\left.<100 \mathrm{mgl}^{-1}\right)$, at this condition the inhibition term can be ignored $\left(S>>K_{\mathrm{SI}}\right)$ therefore the Equation 1 can be renovated as follows .

$$
\begin{aligned}
& R_{S 0}=\frac{k X_{0} S_{0}}{K_{S}+S_{0}}=\frac{R_{m 0} S_{0}}{K_{S}+S_{0}} \\
& R_{X 0}=\frac{R_{S 0}}{X_{0}}=\frac{k S_{0}}{K_{S}+S_{0}}
\end{aligned}
$$

Where, $\mathrm{Rmo}=\mathrm{kXo}$ represents the maximum rate of 4-CP biodegradation (mg 4-CP 1-1h-1). At a initial concentration of 4-CP lower than $100 \mathrm{mgl}-1$, the equation 3 can be expressed in double reciprocal form as follows.

$$
\frac{1}{R_{X 0}}=\frac{1}{k}+\frac{K_{S}}{k} \frac{1}{S_{0}}
$$


From Equation 5 the slope of plot between 1/Rxo versus $1 /$ So represents value of $\mathrm{KS} / \mathrm{k}$ where as the value of $1 / \mathrm{k}$ can be calculated from the intercept of the straight line. Figure 2 demonstrates the plot between $1 /$ Rxo versus $1 /$ So at $4-\mathrm{CP}$ concentration less than $100 \mathrm{mgl}-1$.

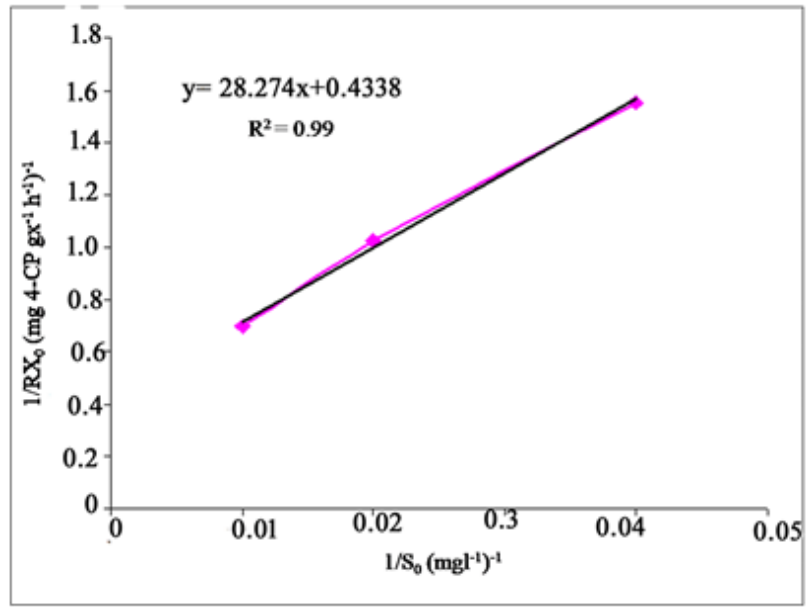

Figure 2 Double reciprocal plot of $1 / \mathrm{Rx} 0$ versus $1 / \mathrm{SO}$ at 4-CP concentration less than $100 \mathrm{mgl}-1$.

From the slope and intercept of the best-fit line with very high determination coefficient value $\left(R^{2}=0.99\right)$ the following values were found. The 4-CP biodegradation rate constant $(k)$ was calculated to $2.3 \mathrm{mg} 4-\mathrm{CPgX}^{-1} \mathrm{~h}^{-1}$ from the intercept of the best-fit line. Similarly half saturation constant $\left(K_{\mathrm{S}}\right)$ was estimated to be $65.17 \mathrm{mgl}^{-1}$. When the concentration of 4-CP beyond $100 \mathrm{mgl}^{-1}$ the first term of equation (1) can be ignored $\left(S>>K_{S}\right)$ and the substrate inhibition term becomes the rate determining factor. Therefore, when the concentration of 4-CP is more than 100 $\mathrm{mgl}^{-1}$, rate equation can be expressed as follows.

$$
\begin{aligned}
& R_{S 0}=k X_{0} \frac{K_{S I}}{K_{S I}+S_{0}} \\
& \frac{1}{R_{X 0}}=\frac{R_{S O}}{X_{0}}=\frac{k K S_{S I}}{K_{S I}+S_{0}}
\end{aligned}
$$

The linear form of the Equation 6 can be expressed as follows:

$$
\frac{1}{R_{X 0}}=\frac{1}{k}+\frac{S_{0}}{k K_{S I}}
$$

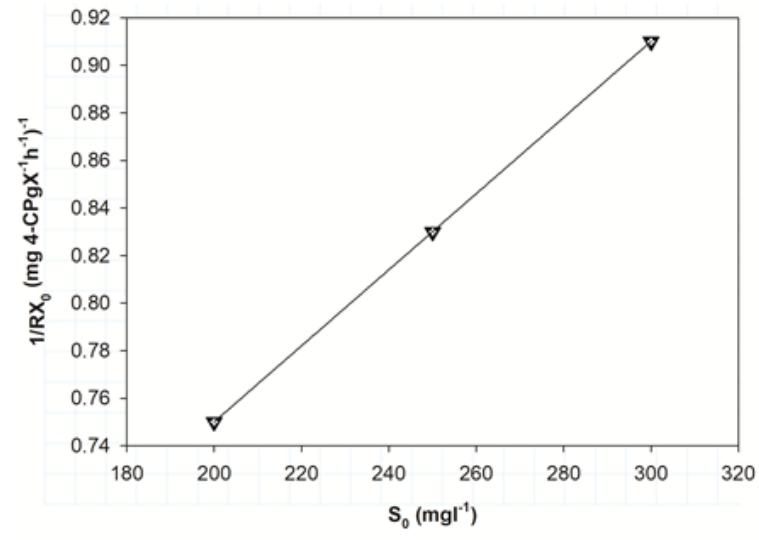

Figure 3. Double reciprocal plot between $1 / \mathbf{R x 0}$ versus initial 4-CP (S0) concentration at higher range.

Figure 3 represents the plot between 1/Rxo versus So at 4$\mathrm{CP}$ concentration more than $100 \mathrm{mgl}-1$. However, 4-CP concentration $350 \mathrm{mg}-1$ was not included in the model as the biodegradation rate since was very less and not fitting for this model in this experiment. The slope of the best fitted line with high determination coefficient $(\mathrm{R} 2=0.99)$ represents $(1 /(\mathrm{kKSI})$ and the intercept of the best fitted line correspond to the rate constant $(1 / \mathrm{k})$. The 4-CP biodegradation rate constant $(\mathrm{k})$ was calculated to $2.3 \mathrm{mg} 4$ $\mathrm{CPgX}-1 \mathrm{~h}-1$ from the intercept of the best-fit line. Similarly inhibition constant (KSI) was calculated to be $271.7 \mathrm{mgl}-1$.

An effort has been made to compare the kinetics parameters estimated in the present study with that of the literature reported values. The magnitude of half saturation constant (Ks) indicates the degree of affinity of 4-CP to the cells of A. chloropehnolicus A6 its growth. The estimated Ks value $(65 \mathrm{mgl}-1)$ is lower than with that of the literature reported values in the range of 75.7- $92.4 \mathrm{mgl}-1$ for biodegradation of phenolic compounds by pure and mixed cultures system [13-15]. The lower value of half saturation constant obtained in the study (65 mgl-1) indicates the higher affinity of 4-CP to the cells of the microorganism for its growth. A lower half saturation constant indicates that, 4$\mathrm{CP}$ is more readily degraded utilized by the $\mathrm{A}$. chloropehnolicus A6. In the present investigation, the higher specific degradation rate of $2.3 \mathrm{mg} 4-\mathrm{CP} \mathrm{gX}-1 \mathrm{~h}-1$ acquired might be due to the A. chloropehnolicus A6 biomass shunting quite a smaller amount of the electrons for the restoration of NADPH, which is typically used for activation of the monooxygenase enzyme system involved with biodegradation of phenolic compounds compared to other bacterial system. However, further investigation is necessary to authenticate this feature. The magnitude of kinetic parameter KSI indicates the degrees of toxicity tolerance of the cells of the microorganisms to the concentration of 4CP. Larger the KSI value indicates toxicity tolerance of microorganism to substrate is very high. In general for degradation of phenolic compounds by different microbial system the reported KSI values in the range of 37.75 to 400 mgl-1 [15, 16, 17, 18]. The larger KSI value (272 mgl-1) obtained in the present study reveals 4-CP toxicity tolerance of the A. chloropehnolicus A6 is found to be very high. The maximum rate of 4-CPdegradation is estimated by applying the following kinetics model at an optimum substrate concentration of Smax $=($ KSKSI $) 1 / 2=(65 \times 272) 1 / 2=133$ mgl-1.

\section{CONCLUSIONS}

The present study revealed that Achlorophenolicus A6 could be employed for treatment of wastewater contaminated with 4-CP efficiently within a short period of time and at a very high concentration i.e. $350 \mathrm{mgl}-1$. The rate of 4-CP degradation decreases with rise initial 4-CP concentrations due to toxic effects of $4 \mathrm{CP}$ exhorted on microbial cell at its higher initial concentration. The experimental results of substrate inhibition kinetic values are better fitted with Pamukoglu and Kargi model. High inhibition constant $(\mathrm{KSI}=273 \mathrm{mg}-1)$ with a $\mathrm{KSI} / \mathrm{KS}$ ratio of 4.18 indicates superior 4-CP biodegradation potential of the

Published By: Blue Eyes Intelligence Engineering \& Sciences Publication

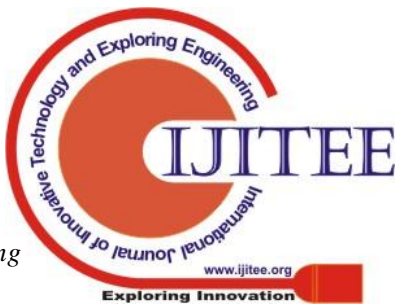


A chlorophenolicus A6. Biokinetic parameters obtained in the study for degradation 4-CP were close agreement with that of literature reported values. The biokinetic parameters obtained in the study will invariably useful in design and operating of bioreactor system for treatment of industrial wastewater contaminated with phenolic pollutants.

\section{REFERENCES}

1. A. Eslami, M., Hashemi, F., Ghanbari, "Degradation of 4-chlorophenol using catalyzed peroxymonosulfate with nano-MnO2/UV irradiation: toxicity assessment and evaluation for industrial wastewater treatment", J. Clean. Prod., vol. 195, pp. 1389-1397, 2018.

2. N.K. Sahoo, K. Pakshirajan, P.K. Ghosh and A. Ghosh, "Biodegradation of 4-chlorophenol by Arthrobacter chlorophenolicus A6: effect of culture conditions and degradation kinetics," Biodegradation, vol. 22, No. 2, pp. 275-286, 2011.

3. B.K. Hamad, A.M. Noor, A.R. Afida and M.N.A. Mohd, "High removal of 4-chloroguaiacol by high surface area of oil palm shell-activated carbon activated with $\mathrm{NaOH}$ from aqueous solution," Desalination vol. 257 No. 1-3, pp. 1-7, 2010.

4. K.Z. Guyton, D. Loomis, Y. Grosse, F. El Ghissassi, V. Bouvard, L. Benbrahim-Tallaa, N. Guha, H. Mattock, and K. Straif, "Carcinogenicity of pentachlorophenol and some related compounds," Lancet. Oncol. vol. 2045, pp. 16-18, 2016.

5. E.O. Igbinosa, E.E. Odjadjare, V.N. Chigor, I.H. Igbinosa, A.O. Emoghene, F.O. Ekhaise, N.O. Igiehon and O.G. Idemudia, "Toxicological profile of chlorophenols and their derivatives in the environment: The public health perspective," The Sci. World J. vol. 2013, pp. 1-11, 2013.

6. T. Ge, J. Han, Y. Qi, X. Gu, L. Ma, C. Zhang, S. Naeem and D. Huang, "The toxic effects of chlorophenols and associated mechanisms in fish," Aquat. Toxicol., vol. 184, pp. 78-93, 2017.

7. SR. Wild, S.J. Harrad and K.C. Jones, "Chlorophenols in digested U.K. sewage sludges," Water Res., vol. 27, pp. 1527-1534, 1993.

8. WHO, "Guidelines for drinking-water quality, Health criteria and other supporting information," World Health Organization, vol. 2 Geneva, 1985.

9. J.S. Ra, S.Y, Oh, B.C. Lee and S.D. Kim, "The effect of suspended particles coated by humic acid on the toxicity of pharmaceuticals, estrogens, and phenolic compounds," Environ. Int., vol. 34, pp. 184-192, 2008.

10. M. Ferraroni1, M.P., Kolomytseva, P.I. Solyanikova, A. Scozzafava1, L.A. Golovleva and F. Briganti, "Crystal Structure of 3-Chlorocatechol 1,2-dioxygenase Key Enzyme of a New Modified Ortho-pathway from the Gram-positive Rhodococcus opacus 1CP Grown on 2chlorophenol," J. Mol. Biol. vol. 360, pp. 788-799, 2006.

11. N.K. Sahoo, K. Pakshirajan and P.K. Ghosh, "Enhancing the biodegradation of 4-chlorophenol by Arthrobacter chlorophenolicus A6 via medium development," Int. Biodeterior. Biodegrad., vol. 64 pp. 474-480, 2010.

12. M.Y. Pamukogluand F. Kargi, "Biodegradation kinetics of 2,4,6-trichlorophenol by Rhodococcus rhodochrous in batch culture," Enz. Microb. Technol., vol. 43, pp. 43-47, 2008.

13. P. Saravanan, K. Pakshirajan and P. Saha, "Batch growth kinetics of an indigenous mixed microbial culture utilizing m-cresol as the sole carbon source," J. Hazard. Mater. vol. 162, pp. 476-481, 2009.

14. M.E. Acuña-Arguielles, P. Olguin-Lora and E. RazoFlores, "Toxicity and kinetic parameters of the aerobic biodegradation of the phenol and alkylphenols by a mixed culture," Biotechnol. Lett., vol. 25, pp. 559-564, 2003.

15. M. Maeda, A. Itoh, Y. Kawase, "Kinetics for aerobic biological treatment of o-cresol containing wastewaters in a slurry bioreactor: Biodegradation by utilizing waste activated sludge," Biochem. Eng. J., vol. 22, pp. 97-103, 2005.

16. A. Kumar, S. Kumar and S. Kumar, "Biodegradation kinetics of phenol and catechol using Pseudomonas putida MTCC 1194," Biochem. Eng. J., vol. 22, pp. 151159, 2005.

17. R.K. Singh, S. Kumar, S. Kumar, A. Kumar, "Biodegradation kinetic studies for the removal of $\mathrm{p}$ cresol from wastewater using Gliomastix indicus MTCC 3869," Biochem. Eng. J. vol. 40, pp. 293-303, 2008.

18. S. Bera, S.A. Roy, and K. Mohanty, "Biodegradation of phenol by a native mixed bacterial culture isolated from crude oil contaminated site," Int. Biodeterior. Biodegrad., vol. 121, pp. 107-113, 2017.

\section{AUTHORS PROFILE}

Authar-

N.K. Sahoo is working as an Associate Professor in the Department of Department of Chemistry Environmental Science and Technology Programme, Institute of Technical Education and Research, Siksha'O'Anusandhan, Deemed to be University, India, After M-Tech in Biotechnology from Jadavapur University, Kolkata India, he has received his PhD from Centre for the Environment from Indian Institute of Technology Guwahati, India. His research interests are in the area of industrial wastewater treatment using photo catalytic nano-composites, nano-adsorbent and bioremediation techniques. He has published over 20 papers in peer reviewed international journals book and book chapter. He is a invited reviewer of many scientific journals including , CLEAN - Soil, Air, Water, Wiley publisher, International Journal of Hydrogen Energy, Elsevier Publisher, Industrial and Engineering and Chemistry Research, ACS, Publisher, Biodegradation, Springer publisher, Chemical Technology and Biotechnology, Wiley publisher, Review in Environmental Science and Biotechnology, Springer publisher, Environmental Process Springer publisher. He is life member of biotechnology society of India 